\title{
Our Conflict-Ridden Globe and How to Win a Better Future for a Globalized World
}

Peter Maurer

\begin{abstract}
Nearly 160 years ago, the International Committee for the Red Cross (ICRC) was founded. Together with the Red Crescent Movement, both have wanted to combine mitigating measures for victims with respect for norms, principles and policies protecting civilians. All the signs today point to global chronic instability. This is driven by unresolved global and regional power competition; fragmentation and proliferation of nations; marginalization and stigmatization of populations in the aftermath of wars and slow, or non-existent, post-war reconstruction. In early 2021 the ICRC has identified around 90 ongoing armed conflicts. There is an urgent need to build on the experiences of the past few decades and forge innovative responses: (1) Putting human security at the center of our concerns and reconciling humanitarian, security, stability and peace-building agendas. (2) Engaging in quiet but robust dialogue with the armed actors of today's conflicts. (3) Identifying humanitarian issues that can build minimal trust between the parties to break cycles of violence. And (4) striving for new forms of diverse partnerships to find a way through political stalemates. When discussing the political, security and strategic issues of concern to the world, it is urgent to keep human security as our focus. Without human security, we risk chronic instability and cycles of violence without end.
\end{abstract}

Keywords International Committee for the Red Cross (ICRC) $\cdot$ Red Crescent Movement - Global chronic instability $\cdot$ Unresolved global and regional power competition - Fragmentation and proliferation of nations $\cdot$ Marginalization and stigmatization of populations • Non-existent post-war reconstruction $\cdot$ ICRC has identified around 90 ongoing armed conflicts • Putting human security at the center $\cdot$ Engaging in quiet but robust dialogue with the armed actors •

Humanitarian issues can build minimal trust between the parties to break cycles of violence $\cdot$ Striving for new forms of diverse partnerships to find a way through political stalemates

P. Maurer $(\otimes)$

The International Committee of the Red Cross (ICRC), Geneva, Switzerland

(C) The Author(s) 2021

H. Wang and A. Michie (eds.), Consensus or Conflict?, China and Globalization,

https://doi.org/10.1007/978-981-16-5391-9_12 


\section{COVID-19 Has Been a Catalyst for a More Fragile World}

As the President of ICRC, the question I am most often asked in interviews is: "What are the concerns that keep you up at night?"

My greatest concern is not one single issue or place, but the "death by a thousand cuts" inflicted upon too many people in conflict zones over too many years.

All the signs today point to chronic instability. This is driven by global and regional power competitions; fragmentation and proliferation of actors; marginalization and stigmatization of populations in the aftermath of wars and slow; or non-existent, reconstruction after wars.

In early 2021, ICRC identified around 90 ongoing armed conflicts. Some have lasted for decades without political solutions, such as Afghanistan. Other conflicts feature more intensified forms of asymmetric violence such as in Burkina Faso. Some of the trends we are observing include:

- Wars are lasting longer than they did two decades ago. The ICRC's early work focused on short-term emergency situations. However, over the years our involvement has become more long term. ICRC's ten largest operations are in protracted armed conflicts, some lasting for decades.

- Wars are increasingly fought in densely populated urban areas, such as the Gaza Strip, Mogadishu, Mosul or Idlib. However, the weapons used are often designed for open battlefields. Weapons with explosive charges and large blast areas, such as artillery and rocket launchers, can mean the risk of civilian casualties is high. Urban conflicts inflict long-term damage, or entirely destroy, the basic infrastructure including the water and electricity supply along with markets, workplaces and schools.

- The root causes of conflicts are becoming increasingly complex and difficult to tackle - they are often a tangled web of politically motivated violence, terrorism, social violence and white-collar crime.

- Armed groups have become more numerous and radical but are also more fragmented. Today, only a third of all conflicts involve two sides, while more than a fifth involves ten or more parties. This makes our core work-namely promoting respect for international humanitarian law and negotiating access to victims-far more complicated.

- These developments are taking place on a stage where longstanding social problems are creating a perfect storm: developmental deficits and injustice, climate change and failed governance at all levels are an expression of these multi-layered threats. You can see the fragility, the deep inequalities and desire for political change in many societies right now through the wave of protests around the globe.

The global pandemic has been an additional accelerating force of existing fragilities.

Health systems, like those in Yemen, were already operating at less than $50 \%$ capacity of what was needed. As countries shifted their focus to address COVID-19, 
other health issues were neglected-from childhood vaccinations to the treatment of chronic diseases and mental health services.

The three pieces of preventative advice-_wash your hands; keep your distance from others; stay at home"-was irreconcilable in the displacement camps and the prisons where the ICRC works, places where clean water is scarce, overcrowding a way of life and home a distant memory for the millions of long-term displaced.

As economic crises hit communities, those on the edges are pushed further behind. Discrimination and ostracization are daily realities for millions of people. Exclusion occurs at multiple levels:

- People are locked out of economic participation, or education.

- Others are excluded in the name of punishment - those accused of committing terrorist acts, detained without judicial process, those perceived to be affiliated with the enemy, including families of foreign fighters.

A desire for revenge may be understandable when years of conflict and atrocities have divided communities, but history shows that policies and practices that are driven by short-term considerations and stigmatize parts of the population work against long-term stability.

\section{A Renewed Partnership for Respect}

It is clear that we need to do things differently.

Our decades of experience tell us that a focus on security without a focus on the human dimension of conflict is in fact no security at all.

The ICRC was founded almost 160 years ago, and from the very beginning, the ICRC has been about much more than the delivery of emergency aid. Humanitarian assistance is necessary to help people survive, but not enough to break a vicious cycle: changing belligerents' behavior to prevent further violence and violations of norms and to bring normality back to societies is essential.

This is not wishful thinking. Policies and behaviors that accord with International Humanitarian Law (IHL) and humanitarian action are practical ways to leave vicious cycles behind and take pathways to peace. Civilian populations must not become the hostages of political and security disagreements.

That's why I am proposing today a renewed and re-energized partnership of engagement through which we can work together to turn the tide.

What would such a partnership look like? 


\section{Neutral, Independent and Impartial Humanitarian}

Neutral, independent and impartial humanitarian work and its contribution to stability is a critical building block for such a partnership.

For centuries, societies have known that there must be limits to the violence that is inflicted on another side because of the lasting divisions that can be difficult to heal. International humanitarian law is built on longstanding customary norms and rules to ensure there is a minimum of humanity.

Even in the deadliest of conflicts the ICRC, as a neutral intermediary, sees how shared humanitarian objectives can help parties find common ground, whether through exchanges of prisoners, evacuation of the wounded, cross-line humanitarian activities or the respectful exchange of human remains.

The ICRC is called on to facilitate these mutual trust-building measures. In October 2020, in what UN Special Envoy Martin Griffiths described as an "airlift of hope", we facilitated the return of more than 1,000 people detained in relation to the conflict in Yemen. The release operation was the result of two years of talks and many years of trust-building with the parties, building on the Stockholm Agreement of late 2018. There is hope that with enough confidence-building measures such as this could pave the way for progress on a wider peace agreement.

Front-line humanitarian action can be a stabilizing factor to hold back development losses. For example, in Syria, as the war shifted into a new phase, we adopted a two-track approach—providing food and shelter to displaced populations while also working in more stable areas to repair water and electricity infrastructure so that people will have basic services when they return. We also ramped up our microeconomic initiatives to prepare the way for a return to regular economic life.

Let there be no doubt that professional humanitarian work extends far beyond delivering bags of food. There are critical skills involved in negotiating access and acceptance and navigating political and societal tensions. The principle of impartiality means we must first look at those who are most in need, most vulnerable and hardest to reach.

It is difficult to imagine former enemies living as neighbors. But we must ask ourselves: what can be done so that people, often women and children, have hopes for the future rather than wait to be molded into the fighters of tomorrow? Boys, without education, health or a chance in life can-and have-grown up to become men with guns.

For instance, with approval from Iraqi authorities, the ICRC is taking steps to help groups of women and children return to their communities. The process is as important as the result. Through community mediation, we work with community leaders to help foster acceptance of their return. We help both the returnees and the existing community to rebuild and to set up microeconomic initiatives. This broad approach is vital for social repair: a small income can protect returnees falling into destitution or homelessness that could lead to further ostracization. Our aims, always, are to reduce points of friction, in the absence of which, communities can begin to heal themselves. 
The ICRC is also working hard in many contexts to find answers for families of missing people who are desperately searching for news. The issue of missing people haunts many regions - and is one of the most critical for reconciliation. We estimate that it affects millions: our staff are overwhelmed by mothers asking for their sons, husbands searching for their wives.

It is an issue that can leave deep scars in communities, but it is also one where parties can reach mutual agreements on humanitarian grounds to share information or allow the return of remains.

Despite the clear contribution of humanitarians to alleviating suffering, laying the groundwork for stabilization, humanitarian work remains severely underfunded. This is compounded today as the COVID-19 pandemic sees some donor states reallocate funds to domestic issues. The truth is that this year, for ICRC's many operations, like those in Iraq and Afghanistan, are underfunded. These shortfalls come at a time when we see people's needs skyrocketing and economic crises looming.

\section{New Pathways for Humanitarian Action}

Conflict dynamics over the last few decades have severely destabilized whole regions, and it seems unlikely that humanitarian action can be financed in the future by transferring money from only a few states to humanitarian organizations.

While serious discussions on burden-sharing, enlarging the donor base and strengthening local actors are necessary, we need a re-imagined approach.

Given the huge financial and innovative capacity in regions like Asia, new and more innovative forms of assisting people should start here:

- Today, it is better to help affected populations through income-generating activities than by making them "beneficiaries", dependent on traditional aid.

- In many places, it is better to replace aid delivered by trucks with cash transfers to those in need, thereby also preserving people's independence and agency.

- It is more important to build on the potential of the digital economy to do needs assessments for people than to design humanitarian action as the low-tech and low-quality end of assistance. Telemedicine can help reach remote areas; big data analysis allows for sharper assessment of needs; virtual training can teach soldiers how to comply with IHL in real combat situations and science enables us to deliver better orthotic and prosthetic services to those affected by violence and conflict.

- Creating new financial instruments based on impact philanthropy and impact investment can fill an important gap today, which will not be addressed by traditional forms of finance.

In all these areas, we have taken a leading role in the humanitarian sector over the past few years. It is also our hope to bring high-tech solutions to low-tech and unstable countries to achieve greater stability for individuals and whole communities. 


\section{Innovation for Improved Action Scale}

There is also a need for increased innovation in the ways in which we deliver humanitarian service. While the ICRC may not have labeled it as "innovation", throughout its 156-year history, ICRC delegates have sought to diagnose problems creatively and improve practice and methods; for example, over a century ago, by creating new treaties in response to the first aerial bombings and chemical weapons attacks in the First World War, or by running international competitions to source the best ideas to perfect the design of stretchers and field hospitals.

Today, digital technologies have the potential to revolutionize the way we work, such as using big data for analysis of people's needs. This initiative allows us to better anticipate conflict dynamics, migratory flows and people's needs, and therefore to deliver a more targeted response.

This is done with full knowledge and awareness of the risks. This is crucial as our mandate to protect victims means that we handle more sensitive data than other organizations. We are currently working with private companies and governments to future-proof and ensure the security of our databases, which contain extremely sensitive data.

At the same time, we are building our own data protection mechanisms, and ICRC is the only humanitarian organization that is a member of the Center for Digital Trust at the Ecole Polytechnique Fédérale de Lausanne (EPFL).

The ICRC is also investing heavily in digitizing our humanitarian services: hightech facial recognition software is helping us to put more families separated by war back in touch. Credit Suisse, as a member of our Corporate Support Group, financially supports the digitalization of family reunification services.

We also need innovative approaches to produce humanitarian products. In cooperation with EPFL, we have developed a new prosthesis for amputees that are not only functionally better but also more cost-efficient.

For the ICRC, cooperation is a crucial aspect of preparing for future challenges. We know that humanitarian solutions are often more effective when they draw on different sectors, approaches and skills, and involve private and public authorities, state bodies and civil society, as well as scientific and practice-oriented organizations. We, therefore, strive to cooperate in numerous areas, including health, biomedicine, energy, water, construction, the logistics supply chain, environmental issues, IT and communications.

The humanitarian challenges that lie ahead are enormous as needs are spiking and capacities to deliver are not matching. Improving what we do by harnessing new technologies and embracing digital transformation is only one thing. We are undoubtedly at the beginning of a new area, in which we will need to adapt our approach in response to people's shifting needs. It will be a long journey for which we need many partners to join us. 


\section{Response of the International System}

The complexity of the issues requires a functioning international system: a system in which states, rather than making empty promises, work together to agree on rules and practical steps forward.

We should also recognize that the future for consensus-building must be not only multi-lateral but also multi-stakeholder, with actors from across sectors coming together to address social issues, rather than to secure political wins.

We are seeing what new platforms can achieve, such as the COVAX alliance, which is bringing together actors from across sectors to work on equitable vaccine delivery.

New forms of partnerships will be critical if we hope to end political stalemates both regionally and globally.

Over the last few decades, we have seen that what happens in a region has an impact on global affairs, and vice versa. From the Israeli-Palestinian conflict and controversial interpretations of the Geneva Conventions over occupation, use of force or terrorism, to the treatment of detainees, the use of chemical weapons or the special cruelty of the fighting in Syria and Iraq - the interplay between regional and global issues is obvious.

It is also true on a more positive note: as recently as last year, the decades-old search for tens of thousands of people who went missing in the Iran-Iraq War and the Gulf War brought - under the leadership of Kuwait - a consensual resolution before the Security Council. Moreover, the resolution recognized IHL, as a key instrument for healing the wounds of war and making pathways to reconciliation.

\section{Engaging with Actors of Influence}

Across the world, the ICRC works hard to build relations with all parties to armed conflicts and those who influence them. Our dialogue aims to secure respect for the laws protecting people in conflict and acceptance for neutral and independent humanitarian action. We also explore opportunities to act as a neutral intermediary and to build belligerents' trust.

Across the world, the ICRC is reaching out to religious circles and schools of thought to better understand the compatibility of the rules governing war and the use of force with religious laws. We are sharing best practices regarding the laws of military operations and the decision-making process in combat and law enforcement operations.

Our lessons learned from working with more than 130 armed forces around the world bring together best practices for protecting and assisting civilians. They are there to be discussed and incorporated into armed forces' training, doctrine, ground rules and practice. 
We have identified several key challenges critical for humanitarian action, in particular: how to deal with security and terrorism, how to engage with non-state armed groups, and how to carry out humanitarian action in the context of partnered, proxy or alliance warfare.

\section{Support Relationships in Armed Conflict}

Today, over a third of non-international armed conflicts involve coalitions of states and/or non-state armed groups. The ICRC has launched a global initiative to work with armed forces and other stakeholders to identify practical measures that will improve the protection of civilians and those hors de combat.

We are collecting and decontextualizing these lessons so that they can be usefully shared with others.

\section{Non-state Armed Groups}

The ICRC also strives to engage with non-state armed groups. The imperative is clear with the rising number of groups: in fact, more armed groups have emerged in the last seven years than in the previous seven decades. This means there is a significant population-tens of millions of people-living outside the reach of state services and in need of humanitarian aid and protection. The ICRC's dialogue with armed groups is therefore critical.

We engage with more armed groups than any other humanitarian organization in the world, both in terms of the number of groups and the extent of our interaction. In a recent study, we identified 614 armed groups of relevance to our operations around the world. Around half of these groups (296) are located in Africa, while 132 are in the Middle East.

These newly emerging armed groups are for the most part decentralized, with less top-down control, but they collaborate with one another and with states within broader strategic alliances. We follow as closely as possible these coalitions, trying to understand their organizational structure as well, to identify decision-makers and the levers of influence on their behavior.

For example, in 2018, after four years of patient work involving intensive consultation with weapon bearers, the ICRC team in Lebanon managed to persuade 27 armed groups active in the refugee camp of Ein el Helweh to sign commitments to protect health care, which resulted in better access for the refugees to treatment.

In other countries, our knowledge and engagement with armed groups are critical to negotiating access to populations in need, ensuring security for communities and our operations, preparing the ground for exchanges of detainees, and in the search for missing people or access to detention facilities. 


\section{Security and Terrorism}

The ICRC is increasingly involved in legal, policy and operational dialogue on finding the acceptable balance between military and security necessities and ensuring people are properly protected under international humanitarian law.

IHL does not pose an undue obstacle to state security. Rather, it offers a framework on dilemmas between humanity and military necessity.

In this regard, the discourse on terrorism deserves a special mention.

The ICRC of course condemns acts of terrorism, whether committed in or outside an armed conflict. Terrorism is anti-humanitarianism. It negates the basic principle of humanity, it goes against the underlying principles and core objectives of IHL.

But in responding to terrorism, IHL strikes a balance between military necessity and considerations of humanity when pursuing a state's security interest.

IHL is there to protect civilian populations affected by terrorism.

Counter-terrorism laws adopted at national, regional and international levels can coexist with IHL and they complement each other, as long as these laws do not generate conflicts of norms and legal confusions, and do not criminalize or unduly restrict humanitarian action.

We realize that in practice there are challenges, which are present in many conflicts and not just in counter-terrorism situations-for instance, distinguishing between fighters and civilians when fighters are hiding among the civilian population. The ICRC has discussions with states around the world on these challenges and seeks to give advice that is as precise as possible and seeks as large as possible a consensus around how to handle some of the difficulties at strategic, tactical and operational levels.

We try to be a pragmatic partner of governments and armed forces, who are confronted with such challenges, rather than a rigid, prescriptive guide. It is through conversation, between weapon bearers and the ICRC, that best practices can be determined and better protection for people affected by conflict and violence can be found.

\section{China's Potential Contribution in Humanitarianism: A Case for the Belt and Road Initiative}

In recent years, China has been championing the Belt and Road Initiative (BRI) as an international public good for many nations that choose to embrace the BRI. In turn, the BRI is equally a platform for China to participate in international governance.

The BRI is about development, and development requires stability and peace. Humanitarian action is contributing to stabilizing societies in some of the most difficult circumstances; it prevents violence to destroy development gains. 
That is why I am deeply convinced the BRI should add a humanitarian dimension, which will be an important building-block to deliver on the UN's Sustainable Development Goals (SDGs). I am also certain and know that the ICRC can share its experience and knowledge and bring added value. For instance, the ICRC provides guidance and shares good practices with Chinese companies operating overseas in fragile environments with the aim of strengthening their corporate social responsibility and mitigating the risk of increased instability.

Humanitarian organizations are investing in building systems and vital infrastructure mostly in the most remote and dangerous places. There is clearly a real prospect in engaging with international financial institutions, such as the World Bank, but also with relevant Chinese stakeholders where, for security reasons, development actors are not in a position to invest in infrastructure.

In the BRI context, it is important to recognize the contribution of humanitarian organizations to:

- Uphold the basic humanitarian principles of neutrality, impartiality and independence through their relations with states and non-state actors.

- Contribute, through short and long-term humanitarian assistance, to the stabilization of countries or regions affected by protracted conflicts and therefore provide the conditions for future development.

In today's complex world, more than ever, China has a role to play and will be a part of the search for solutions, especially through innovative infrastructure, digitalization and information technologies.

\section{Conclusion}

Nearly 160 years ago, the ICRC was founded to make professional humanitarianism a force in the service of modern statehood. Instead of handouts for the poor, the International Red Cross and Red Crescent Movements, throughout their histories have wanted to combine mitigating measures for victims with respect to norms, principles and policies protecting civilians.

This remains key to dealing with the complexities of modern, asymmetric and protracted conflicts, but we need to build on the experiences of the past few decades and forge innovative responses, such as:

- Putting human security at the centre of our concerns and reconciling humanitarian, security, stability and peace-building agendas;

- Engaging in quiet but robust dialogue with the armed actors of today's conflict in order to ensure better respect for laws and principles through practical and pragmatic cooperation;

- Identifying humanitarian issues that can build minimal trust between the parties to break cycles of violence 
- And striving for new forms of diverse partnerships to find a way through political stalemates.

When discussing the political, security and strategic issues of concern to the world, it is urgent to keep human security as our focus.

Without human security, we risk chronic instability and cycles of violence without end.

Peter Maurer is the President of the International Committee of the Red Cross (ICRC). He studied history and international law in Bern, where he was awarded a doctorate. In 2000, he was appointed ambassador and head of the human security division in the political directorate of the Swiss Department of Foreign Affairs in Bern. He was appointed ambassador and permanent representative of Switzerland to the United Nations in New York (2004), Chairman of the Fifth Committee (2009) and Secretary of State for foreign affairs in Bern. Under his leadership, the ICRC carries out humanitarian work in over 80 countries.

Open Access This chapter is licensed under the terms of the Creative Commons AttributionNonCommercial-NoDerivatives 4.0 International License (http://creativecommons.org/licenses/bync-nd/4.0/), which permits any noncommercial use, sharing, distribution and reproduction in any medium or format, as long as you give appropriate credit to the original author(s) and the source, provide a link to the Creative Commons license and indicate if you modified the licensed material. You do not have permission under this license to share adapted material derived from this chapter or parts of it.

The images or other third party material in this chapter are included in the chapter's Creative Commons license, unless indicated otherwise in a credit line to the material. If material is not included in the chapter's Creative Commons license and your intended use is not permitted by statutory regulation or exceeds the permitted use, you will need to obtain permission directly from the copyright holder.

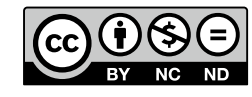

